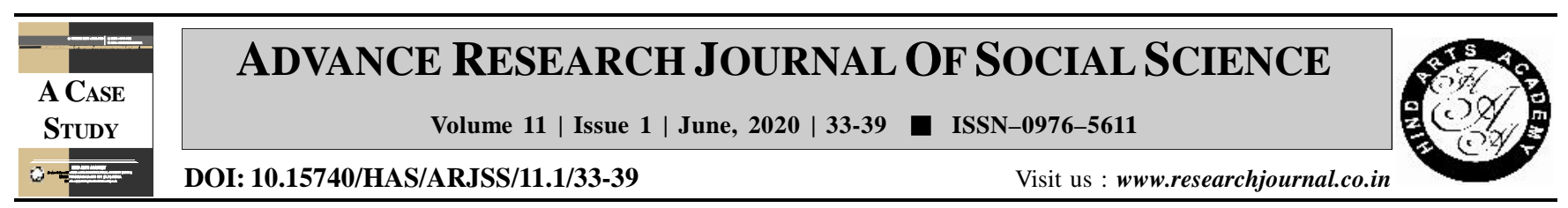

\title{
From MPLADS to SAGY: Changing role of peoples' representatives in grass roots level development in India
}

Sonal Bhatt

Post Graduate Department of Economics, Sardar Patel University, Vallabh Vidyanagar, Anand (Gujarat) India (Email : svbhatt@gmail.com,sv_bhatt@spuvvn.edu)

\section{ARTICLE INFO :}

Received : 28.04 .2020

Accepted : $\quad 25.05 .2020$

KEY WORDS :

MPLADS, SAGY, Rural development

HOW TO CITE THIS ARTICLE :

Bhatt, Sonal (2020). From MPLADS to SAGY: Changing role of peoples' representatives in grass roots level development in India. Adv. Res. J. Soc. Sci., 11 (1): 33-39, DOI: 10.15740/HAS/ ARJSS/11.1/33-39.Copyright@ 2020:Hind Agri- Horticultural Society

\begin{abstract}
This paper makes a comparison between the Member of Parliament Local Area Development Scheme (MPLADS) and Saansad Adarsh Gram Yojana (SAGY) and outlines the difference between the approaches of the two Schemes. It concludes that even as MPLADS and SAGY are tactically similar schemes, the people's representatives have a much greater role as agents of change under SAGY. Participation from village officials and the rural people themselves is also essential for fulfilling the objectives of SAGY.
\end{abstract}

